\title{
Unrest at home: diarrheal disease and microbiota disturbance
}

\author{
Elisabeth M Bik ${ }^{1}$ and David A Relman ${ }^{1,2,3^{*}}$ \\ See related Research; http://genomebiology.com/2014/15/6/R76
}

\begin{abstract}
Diarrhea and malnutrition, two intertwined worldwide problems, are both associated with lower diversity of the intestinal microbiota in children in low-income countries.
\end{abstract}

Diarrheal diseases are a major cause of childhood morbidity and mortality in many parts of the world. In 2010, over seven million children died worldwide before their fifth birthday, and most of them lived in low-income countries in Asia and Africa. One out of ten of these deaths was caused by diarrhea; this is more than the combined number of deaths caused by AIDS, malaria and measles [1]. In this issue of Genome Biology, Pop and colleagues [2] describe the intestinal microbiota of nearly 1,000 children from Bangladesh, The Gambia, Kenya and Mali, half of whom had acute moderate-tosevere diarrhea. Intriguing differences were seen in the compositional state of microbiotas from those with and without diarrhea, and across these four geographic sites.

In the distal gut, the microbiota is relatively simple in the first weeks of life, and is composed of aerobic or microaerophilic bacteria. This microbiota then increases in diversity and gains large numbers of as-yet poorly characterized anaerobes, reaching an adult-like state by approximately three years of age. General features of this assembly process are conserved in children living all over the world [3], although older children and adults living in different parts of the world show marked differences in gut microbiota composition associated with variation in diet, hygienic conditions and cultural traditions [3-5]. The intimate relationship between intestinal

\footnotetext{
* Correspondence: relman@stanford.edu

${ }^{1}$ Department of Microbiology \& Immunology, Stanford University School of Medicine, Stanford, CA 94305, USA

${ }^{2}$ Department of Medicine, Stanford University School of Medicine, Stanford, CA 94305, USA

Full list of author information is available at the end of the article
}

bacteria, diet and nutritional state was also highlighted by Smith et al. [6], who found significant differences between the gut microbiomes of Malawian twins discordant for kwashiorkor, a severe form of malnutrition characterized by edema, hair and skin abnormalities, and liver failure.

A recent report by Subramanian and colleagues [7] sheds more light on the linkage between gut microbiota assembly in early childhood, diarrheal disease and malnutrition. Using a machine learning approach, the authors created a model for healthy microbiota development that calculates a microbiota maturity index trained on bacterial taxonomic biomarkers in stool samples from healthy, well-nourished Bangladeshi children at monthly time points during the first two years of life. Using this model, they found that diarrheal disease in well-nourished children was associated with a transient decrease in the microbiota maturity score that had resolved a month or two later. In contrast, severe acute malnutrition was associated with a more prolonged delay in gut microbiota maturation that was only partially corrected by food interventions. Their work suggests the importance of microbiota assembly patterns as reflections of underlying host nutritional status, and gut ecosystem disturbance.

The Global Enteric Multicenter Study (GEMS) was established in order to identify the causes and effects of childhood diarrhea. This three year prospective study was conducted at seven sites in sub-Saharan Africa and South Asia with moderate-to-high mortality among children in their first five years of life. Stool samples from 9,439 children with moderate-to-severe diarrhea and 13,129 age-matched, gender-matched and residencematched controls without diarrhea were tested for a wide array of viral, bacterial, and parasitic pathogens. In $43 \%$ of the moderate-to-severe diarrhea cases, one or more pathogens were detected [8], most notably rotavirus, Cryptosporidium, enterotoxigenic Escherichia coli producing heat-stable toxin, and Shigella. At the time of 
clinical follow-up, children who had experienced a diarrheal episode showed a greater lag in height development than their age-matched controls. In addition, the diarrheal episode was associated with a more than eightfold increased risk of death during the follow-up period [8].

Although GEMS was an important step forward in determining the causes and effects of diarrheal diseases in low-income countries, many questions remained unanswered. In about half of the diarrheal cases, conventional diagnostic tests failed to reveal a known pathogen, suggesting that the diarrhea might have been caused by yet unrecognized pathogens, or that other factors might play a role, including disrupted gut permeability, and alterations in the composition and function of the gut microbiota.

Pop and colleagues [2] analyzed the taxonomic composition of the intestinal microbiota of 992 children enrolled in GEMS, based on the sequences of amplified small subunit ribosomal RNA genes present in stool specimens. All children were under five years of age and lived in four of the seven GEMS low-income sites, spanning a wide range of cultural and dietary traditions. Of these 992 children, 508 had acute diarrhea at the time of specimen collection, and the rest were controls. The incorporation of subjects from disparate geographic regions of the world is a particularly valuable aspect of this study. As in children from other studies [3], overall fecal bacterial diversity increased with age in both healthy controls and cases, with a gradual increase in Prevotella and a decrease of Escherichia, Veillonella and Streptococcus species. In all age groups, the microbiota of GEMS-enrolled children presenting with acute diarrhea displayed lower taxonomic diversity than that of their age-matched healthy controls [2], similar to the findings of reduced diversity by Subramanian et al. [7] in healthy Bangladeshi children with diarrhea. Since no time series were conducted by Pop et al., it is not clear if this reduced diversity associated with diarrhea was transient or prolonged, and/or whether it might have preceded the onset of diarrhea. Related issues concern the absence of information about the numbers, timing and severity of prior episodes of diarrheal disease in all of these children, their nutritional state, as well as the absence of information about antibiotic treatment. Because these factors help to shape the ecological fitness landscape of the gut, they might easily confound the findings in this study.

Many of the diarrheal case-associated bacterial taxa identified by Pop and colleagues [2] were bacteria known to be capable of causing diarrheal disease, and previously found in this cohort with conventional diagnostic tests [8], such as Escherichia/Shigella and Campylobacter jejuni. The microbiota analysis also implicated other genera, such as Streptococcus and Granulicatella, in diarrheal disease. Other bacterial taxa were negatively associated with diarrhea, including Prevotella and Lactobacillus ruminis [2]. Importantly, as discussed by the authors, the diarrhea-associated taxa are not necessarily the cause of the diarrhea, or even a contributory factor. They may have 'bloomed' because of altered gut conditions, or become disproportionately represented in stool because of faster gut transit time.

Breaking through the downward spiral of malnutrition and diarrhea in developing countries is tough. Unfortunately, malnutrition, poor hygienic conditions and diarrhea are tightly connected and synergistic; solving one problem without addressing the others might not lead to improvements. Chronic exposure to pathogens can lead to intestinal inflammation and ultimately to a condition called environmental enteropathy in which the gut microvilli architecture is damaged and energy absorption capacity is disturbed. The effects of this condition on the intestinal microbiota are not yet clear, but it is likely to affect its taxonomic composition.

Dense longitudinal studies of the gut microbiota, in the context of host health and malnutrition, and diarrhea in low-income countries, in addition to studies that monitor immune system and gut permeability markers, are needed to identify microbiota members and products that might be exploited to reduce disease and promote health. For example, Salmonella, a leading cause of gastroenteritis, thrives in the inflamed gut by expressing a siderophore that helps it scavenge effectively for iron. The addition of the non-pathogenic Escherichia coli strain Nissle 1917, which uses a similar siderophore system to compete with Salmonella for iron acquisition in the face of induced host iron scavenging systems, reduces Salmonella colonization in mouse models [9]. Similar approaches for exploiting and manipulating natural competitive interactions in the gut might be employed for management of childhood diarrhea and promoting healthy microbiota configurations. Forwardlooking strategies for intestinal ecosystem restoration in the aftermath of diarrheal disease, and for preservation of ecosystem services during childhood, will require a careful examination of the roles played by prior stochastic and historical events, and gut environmental selection, in the assembly of the gut microbiota [10].

\section{Abbreviation}

GEM: Global Enteric Multicenter Study.

\section{Competing interests}

The authors declare that they have no competing interests.

\section{Acknowledgements}

DR was supported in part by the National Institutes of Health (Al112401, GM099534, DE023113), Office of Naval Research (N000141010233), and by the Thomas C and Joan M Merigan Endowment at Stanford University. 


\section{Author details}

'Department of Microbiology \& Immunology, Stanford University School of Medicine, Stanford, CA 94305, USA. ²Department of Medicine, Stanford University School of Medicine, Stanford, CA 94305, USA. ${ }^{3}$ Veterans Affairs Palo Alto Health Care System, Palo Alto, CA 94304, USA.

\section{Published: 27 June 2014}

\section{References}

1. Liu L, Johnson HL, Cousens S, Perin J, Scott S, Lawn JE, Rudan I, Campbell H, Cibulskis R, Li M, Li M, Mathers C, Black RE, Child Health Epidemiology Reference Group of WHO and UNICEF: Global, regional, and national causes of child mortality: an updated systematic analysis for 2010 with time trends since 2000. Lancet 2012, 379:2151-2161.

2. Pop M, Walker AW, Paulson J, Lindsay B, Antonio M, Hossain MA, Oundo J, Tambora B, Mai V, Astrovskaya I, Corrada Bravo H, Rance R, Stares M, Levine MM, Panchalingam S, Kotloff K, Ikumapayi UN, Ebruke C, Adeyemi M, Ahmed D, Ahmed F, Alam MT, Amin R, Siddiqui S, Ochieng JB, Ouma E, Juma J, Mailu E, Omore R, Morris JG, Breiman RF, Saha D, Parkhill J, Nataro $J P$, Stine OC: Diarrhea in young children from low-income countries leads to large-scale alterations in intestinal microbiota composition. Genome Biol 2014, 15:R76.

3. Yatsunenko T, Rey FE, Manary MJ, Trehan I, Dominguez-Bello MG, Contreras M, Magris M, Hidalgo G, Baldassano RN, Anokhin AP, Heath AC, Warner B, Reeder J, Kuczynski J, Caporaso JG, Lozupone CA, Lauber C, Clemente JC, Knights D, Knight R, Gordon Jl: Human gut microbiome viewed across age and geography. Nature 2012, 486:222-227.

4. De Filippo C, Cavalieri D, Di Paola M, Ramazzotti M, Poullet JB, Massart S, Collini S, Pieraccini G, Lionetti P: Impact of diet in shaping gut microbiota revealed by a comparative study in children from Europe and rural Africa. Proc Natl Acad Sci U S A 2010, 107:14691-14696.

5. Lin A, Bik EM, Costello EK, Dethlefsen L, Haque R, Relman DA, Singh U: Distinct distal gut microbiome diversity and composition in healthy children from Bangladesh and the United States. PLoS One 2013, 8:e53838.

6. Smith MI, Yatsunenko T, Manary MJ, Trehan I, Mkakosya R, Cheng J, Kau AL, Rich SS, Concannon P, Mychaleckyj JC, Liu J, Houpt E, Li JV, Holmes E, Nicholson J, Knights D, Ursell LK, Knight R, Gordon JI: Gut microbiomes of Malawian twin pairs discordant for kwashiorkor. Science 2013, 339:548-554.

7. Subramanian S, Huq S, Yatsunenko T, Haque R, Mahfuz M, Alam MA, Benezra A, DeStefano J, Meier MF, Muegge BD, Barratt MJ, VanArendonk LG, Zhang Q, Province MA, Petri WA Jr, Ahmed T, Gordon Jl: Persistent gut microbiota immaturity in malnourished Bangladeshi children. Nature 2014, doi:10.1038/nature13421.

8. Kotloff KL, Nataro JP, Blackwelder WC, Nasrin D, Farag TH, Panchalingam S, Wu Y, Sow SO, Sur D, Breiman RF, Faruque AS, Zaidi AK, Saha D, Alonso PL, Tamboura B, Sanogo D, Onwuchekwa U, Manna B, Ramamurthy T, Kanungo S, Ochieng JB, Omore R, Oundo JO, Hossain A, Das SK, Ahmed S, Qureshi S, Quadri F, Adegbola RA, Antonio M, et al: Burden and aetiology of diarrhoeal disease in infants and young children in developing countries (the Global Enteric Multicenter Study, GEMS): a prospective, case-control study. Lancet 2013, 382:209-222.

9. Deriu E, Liu JZ, Pezeshki M, Edwards RA, Ochoa RJ, Contreras H, Libby SJ, Fang FC, Raffatellu M: Probiotic bacteria reduce salmonella typhimurium intestinal colonization by competing for iron. Cell Host Microbe 2013, 14:26-37.

10. Costello EK, Stagaman K, Dethlefsen L, Bohannan BJ, Relman DA: The application of ecological theory toward an understanding of the human microbiome. Science 2012, 336:1255-1262

doi:10.1186/gb4182

Cite this article as: Bik and Relman: Unrest at home: diarrheal disease and microbiota disturbance. Genome Biology 2014 15:120. 